The Editors welcome topical correspondence from readers relating to articles published in the fournal. Letters should be submitted electronically via the B7S submission site (mc.manuscriptcentral.com/bjs). All correspondence will be reviewed and, if approved, appear in the fournal. Correspondence must be no more than 300 words in length.

Author response to:

\section{Covid-19-related pancreatic injury}

Editor

We would like to thank Mukherjee and colleagues $^{1}$ for their insightful comment on our recently published Leading Article $^{2}$.

As the authors correctly pointed out, little is known of the effect of SARS$\mathrm{CoV}-2$ on the pancreas, although some mechanisms can explain it and justify the clinical presentation observed. Data on COVID-19 and knowledge of the disease course are evolving rapidly, justifying the fact that many grey areas exist. Indeed, the authors of a recent pathological report from China found that, even if the damage was located predominantly in the lungs, there were alterations in several other organs, including heart, spleen, liver and bone marrow, with degeneration of some islet cells in the pancreas $^{3}$. Moreover, the rate of patients presenting with abdominal symptoms might have been influenced by the actual number of individuals tested. Interestingly, according to a study performed at Humanitas Hospital, of the first 100 patients admitted to the COVID-19 ward, approximately 15 per cent had diarrhoea; we cannot anticipate how many had increased amylase or lipase on laboratory tests at admission, as data are under analysis (S. Danese, unpublished).

In light of these observations and the comment of Mukherjee et al. ${ }^{1}$, we suggest it is important to capture information on this aspect of the disease by means of ongoing studies on COVID-19 patients, especially those dealing with surgery during the pandemic. The COVIDSurg Initiative is a collaborative research group aimed at clarifying the outcome and features of patients undergoing surgery while COVID-19-positive; several studies are planned, with international collection of data prospectively (https://globalsurg .org/covidsurg/). It is likely that similar initiatives might shed some light on abdominal symptoms and involvement of the gastrointestinal tract associated with COVID-19.

$$
\begin{array}{r}
\text { A. Spinelli }{ }^{1,3} \text { (D) G. Pellino } \\
\text { S. Danese }{ }^{1,2} \\
{ }^{1} \text { Department of Biomedical Sciences, } \\
\text { and }^{2} \text { IBD Center, Department of } \\
\text { Gastroenterology, Humanitas Clinical and }
\end{array}
$$

Research Center - IRCCS -, via Manzoni 56, 20089 Rozzano, Humanitas University, Department of Biomedical Sciences, Via Rita Levi Montalcini 4, 20090 Pieve Emanuele, and ${ }^{3}$ Division of

Colon and Rectal Surgery, Humanitas Clinical and Research Hospital, Rozzano,

Milan, and ${ }^{4}$ Department of Advanced Medical and Surgical Sciences, Università degli Studi della Campania 'Luigi Vanvitelli', Naples, Italy, and ${ }^{5}$ Colorectal Unit, Vall d'Hebron University Hospital, Barcelona, Spain

DOI: $10.1002 / b j s .11648$

1 Mukherjee R, Smith A, Sutton R. Comment on: COVID-19 pandemic: perspectives on an unfolding crisis. $\mathrm{Br}$ 7 Surg 2020; 107. https://doi.org/10 $.1002 /$ bjs. 11645 [Epub ahead of print].

2 Spinelli A, Pellino G. COVID-19 pandemic: perspectives on an unfolding crisis. Br 7 Surg 2020; https://doi.org/ 10.1002/bjs.11627 [Epub ahead of print].

3 Yao XH, Li TY, He ZC, Ping YF, Liu $\mathrm{HW}, \mathrm{Yu}$ SC et al. [A pathological report of three COVID-19 cases by minimally invasive autopsies]. Zhonghua Bing Li Xue Za Zbi 2020; 49: E009. https://doi.org/10.3760/cma.j .cn112151-20200312-00193 [Epub ahead of print]. 